\title{
Hybrid Space and Digital Diplomacy in Global Pandemic Covid-19
}

\author{
Andrik Purwasito ${ }^{1 *}$ Erwin Kartinawati $^{2 *}$
}

\author{
${ }^{I}$ Faculty of Social and Political Sciences, Universitas SebelasMaret, Surakarta, Indonesia \\ ${ }^{2}$ Communication Department, Universitas Sahid Surakarta, Indonesia \\ *Corresponding Author : erwinpurwasito@gmail.com
}

\begin{abstract}
Technological developments have proven the rise of The Global Village. International Relations in the era of technological development also experienced a very fantastic historical leap. The technological revolution has arisen hybrid space, which is when today's space has been changed by the use of the Internet of Things (IoT), the reality of space becomes Augmented Reality (US) and Virtual Reality (VR) but also a combination of both-: Mixed Reality (MR). Hybrid space is an inevitable space, so every actor in international relations must use the digital platform. In the hybrid space, diplomacy and international relations actors, both in terms of relations between countries, relations between non-governmental institutions, between individuals and individuals, are joined and connected in a system that combines technology, communication, and content. Automatically the concepts of diplomacy and international relations undergo fundamental changes, at least new models are born, such as how to organize diplomacy and negotiation from offline and online (digital interaction). International relations during the covid pandemic require the use of the internet as a basis for communication and negotiation. The role of the internet has become very dominant, as the mainstream in relations between nations and between countries. The internet is expected to be dynamic so that international relations and diplomacy become more flexible, high mobility, cheap, fast, and creative. What is described above can be drawn to the problems of how diplomacy and international relations change itself from analogical diplomacy into digital diplomacy, or what is known as virtual diplomacy in the current terms.
\end{abstract}

Keywords: click and share, digital diplomacy, digital interaction, hybrid space, virtual diplomacy.

\section{INTRODUCTION}

The global Covid-19 pandemic has proven to have forced every international actor, both state and non-state actors, to adjust to the new normal situation. It is like a scenario of a future plan so that everyone changes real life to virtual life or what we call hybrid space. The Covid-19 pandemic has forced every actor to submit to this scenario. This is a new life that has started since life entered the millennial era. It is a life that forces everyone to communicate in a new way, a digital interaction. In international relations, actors are also implementing new diplomacy, namely digital diplomacy. A book was written by Corneliu Bjola and Marcus Holmes [1], "Digital Diplomacy: theory and practice," published by Routledge New Diplomacy Studies, concludes that technology has facilitated the practice of digital diplomacy with satisfactory results. The book is an initial reference that describes digital diplomacy as a form of change management in international politics. The second is a book on digital communication and diplomacy, written by Nicholas J Cull, namely "Public
Diplomacy, Foundation for Global Engagement in the Digital Age." On various occasions, diplomats and foreign ministry practitioners often refer to it as a revolution in diplomacy practice. In fact, the digital revolution in international relations was delayed for years because offline activities could still be carried out. Because of the Covid-19 pandemic, like it or not, every state actor is changing their governance and ways of communicating through virtual networks. It is undeniable that digital technology has changed how social relations are carried out, and the state conducts governance internally, but the state only realizes its potential to change the pattern of international relations, as well as socio-economic and political relations, so it must adopt a new normal procedure in all aspects of interaction and communication between actors.

On many occasions, since the emergence of social media such as Youtube, Facebook, Linkedin, Tweeter, WhatsApp, etc, the adoption of diplomacy into the virtual 
world has become increasingly prominent. This is because international political actors often use social media as a way of conveying political ideas and messages. This is what will then become the center of the writer's attention. This is due to the implications of using the internet: social media and webinars or zooming meetings have been proven to change the way and practice of diplomacy, which requires that every representative or embassy of a country abroad needs new strategies, tactics or management, and governance. Thus the practice of negotiation, public diplomacy, and crisis management can adapt to this hybrid diplomacy.

In many cases, the practice of hybrid diplomacy was initially disliked by the institutions or organizations that carry out foreign policy, due to some risks or communication obstacles. However, in the era of the Covid-19 pandemic, the risks and prestige in bilateral and multilateral relations appear more practical. This is due to the ease of communicating internationally, especially the ability of hybrid diplomacy to overcome distance (work from home, less accommodation, transportation, and consumption). All diplomatic activities are held from the home or office of each actor. In this case, we see a high cut in operational funds because all activities can be carried out via the internet network. This means that international actors inevitably have to migrate from desk diplomacy to diplomacy through social media. This new communication practice is massive, both in terms of promoting diplomatic ideas and activities, as well as as a means of sharing information. Facebook, Youtube, Tweeter, Linkedin are used as a means of interacting with the global public. Thus diplomats and non-state actors are forced to enter the era of hybrid space, with the awareness that the new normal in the Covid-19 pandemic is a practice of network diplomacy.

The New Normal Era is to integrate networked diplomacy through this hybrid space. These situations often face cultural barriers, especially in the form of conservative and normative attitudes and behaviors that have been carried out for a long time. This is normal because we face the sudden condition of having to do new practices by working from home or work from the office. Traditional diplomacy is unlikely to be abandoned. Therefore, two diplomatic practices, both on-line and offline, must still be applied. From what is described above it can be formulated the problems faced by international actors in the era of the Covid-19 pandemic, especially the Ministry of Foreign Affairs, namely how do international actors prepare to enter the world of hybrids? Furthermore, what can be done by actors concerning to all forms of barriers, both cultural and technological barriers as well as how actors accelerate the process of adaptation to hybrid diplomacy so that national interests can be optimally achieved?

\section{LITERATURE REVIEW}

This study uses diplomacy theory because it refers to the role of actors in diplomatic activities, both state and non- state actors. These actors have different interests. National interests are achieved by state actors, while special interests outside the state are achieved by organizations and individuals or other interest groups or what are called non-state actors. Diplomacy, as an art of negotiation, is the relationship of various actors in international relations which are held bilaterally or multilaterally. Various forms of diplomacy, such as smart power diplomacy, hard power diplomacy, soft power diplomacy, and nano power diplomacy, are held to achieve the interests. Diplomacy is an arena for communication between actors to ensure their security, pursuing a positive image for themselves[2]. In this paper, diplomacy is focused on the role of the Ministry of Foreign Affairs, namely State actors in achieving national interests through virtual diplomacy.

Another thing that needs to be understood in this paper is the concept of virtual communication. Virtual communication is a form of new era communication. The same is the case with other communication processes, namely a process of delivering messages to other parties only using the media or intermediaries. If previously known as television, radio, newspapers, and other types of media, now along with the development of technology, namely the internet, there are more types of media, namely through or using the internet. The presence of the internet has changed the style of communication and human life. Communication using online media allows relationships to be as interactive as direct communication, but they don't happen in person. Barriers such as distance, time, cost, and other types of difficulty can be ignored. There are two conditions in the virtual communication process, namely asynchronous communication where the sender and delivery of a message interact but not at the same place and time, even though the message is still conveyed. The only condition is synchronous communication where communication occurs at the same time [3].

\section{METHODS}

This type of research is a qualitative research building on observation and notes from social findings of technology, office work, and diplomacy as well as international politics. Considering this, the researchers made a description or theoretical solution model of the phenomena of international politics, technology, and international relations.

In data collection, informants were people or groups of people who provided information on the work performed, their views, and their roles in the office. The selected informants were the people who correlated with the focus and objectives of the research. They were such as the Ambassador and Deputy Ambassador.

This research tried to observe the activities of an office. Researchers interacted intensively to study habits, routine activities, especially in terms of the use of technology, cellular, television, about office tasks. Researchers made detailed observations about office activities or interactions within the Ministry of Foreign Affairs, to understand how they work, interpreted their 
world of work, and extract from several sources who had experience and knowledge of the use of technology for office activities, such as negotiations and diplomacy.

Researchers also interacted with practitioners whose aim was to find information about their views and experiences in the field of use of information and communication technology and social media. Those data then were formulated in the analysis that will be described below. In this case, the researchers served as the main instrument that recorded observations in detail, and then also collected reference data, then interpreted the data to form an analysis strategy and compiled answers to new behaviors in diplomacy and international relations at the Ministry of Foreign Affairs. Finally, this paper was a reflection of thoughts about a phenomenon described above.

\section{RESULT AND DISCUSSION}

To answer this question, several strategies can be carried out by international actors, namely as follows.

\subsection{Willingness and Readiness for digital diplomacy}

Since 2000, when the economic boom and historical acceleration through the development of communication, information, and transportation technology [4], in fact, international relations have started the use of the internet for economic, political, and propaganda purposes. Media in the 1980s has become the most effective and efficient driving force in international relations, especially in efforts to build international cooperation, ideological wars, and national branding[5]. International actors have seen how strong the global communication network is, which is called living in a global village [6]. The development of communication and information technology has narrowed the global world region to become a "global village", which is connected to the internet. The global village has also influenced international relations marked by homogenization in culture, as well as the spread of more polarized power so that the single $G$ to $G$ relationship becomes a global social relationship. This is accompanied by a flood of information with new and confusing communication symbols [7] and followed by an increase in technology and adequate transportation facilities, resulting in multiple speeds at a lower cost. All the booms mentioned above have motivated international actors to migrate from offline to online means or what can be called proactive digital diplomacy.

In a global village, the polarization of information, especially from the movements of global non-state actors, is suspected as a threat to civilization, such as extremism, human trafficking, and drugs and international crimes. The use of advanced technology was demonstrated by allies in the attack on Iraq in 1991. Mainstream Western democratic and secular culture is Western propaganda by relying on online technology instead of conventional strategies and tactics, as they did the Arab Spring project in the Middle East. This shows that the Ministry of Foreign Affairs has utilized technological innovation for diplomacy and war needs. The West sees that technology is the key to shaping future power. Morgenthau called it an element of national power [8]. In practice, the Ministry of Foreign Affairs utilizes technological innovation to establish new norms in routine work and to carry out diplomatic activities. In the end, mastery of technology determines the procedures and practices of diplomacy in all matters, both for management and promotion activities.

\subsection{Creativity and Adaptation to the Digital Environment}

The dynamics of technology and its development are increasingly difficult to predict. Therefore, in the dynamics and changing conditions, the Ministry of Foreign Affairs needs new adaptations that are more dynamic and flexible. Keep in mind that online networks continue to grow while digital sites or platforms will continue to emerge and go, depending on followers and public support. Therefore, the Ministry of Foreign Affairs needs a dynamic strategy and creative connections in online networks, so that under changing conditions, the Ministry is ready to adapt to a new environment. It is hoped that this will continuously maintain the position of branding, negotiation, debate, and the ability to defend truth claims. Therefore, competition for the truth continues to be debated in the future, so the Ministry needs virtual public support. To achieve this, multi-media investment is urgently needed to create advanced human resource capabilities and infrastructure to produce digital visual works.

\subsection{Big Data and Analysis}

The capabilities of human resources and infrastructure are needed to capture data scattered in cyberspace. The discourse that develops in digital diplomacy requires a methodology and parameters capable of displaying the effectiveness of digital diplomacy. The Methodology is important because the results of the analysis are the strength of a country's diplomacy. Of course, systematic and targeted data collection, especially data scattered on social media, actually becomes a voice or public opinion in a particular discourse. Meanwhile, in the rational analysis stage, the Ministry will have conceptual results and results that will have a major influence both internally and on global dynamics and changes. Also according to Bjola [1] that proper analysis has strategic digital tracing power, namely the ability to track the flow of online information and identify how narrative and counternarrative are spreading among the online public. Thus it is hoped that the Ministry will have the ability to overcome crises, political instability, terrorism, transnational crime, and be able to influence the flow of online information. If 
need be, even fight back or spread world views, beliefs, and opinions.

Knowledge and experience in mastering technology and its tools are needed in foreign policy operations. By having good knowledge of big data, the ministry of foreign affairs is able to carry out the diplomacy process well. At least, big data has two types of technology. The first is operational big data, which is a system that has the operational capability to process interactive work with partners through direct and real-time dialogue. The process of dialogue and interactive work is stored and absorbed to be used as material for policymaking. The second, is big data that is analytical, which is a tool that works to analyze data in a sophisticated way, even though the data is scattered and scattered. Both are very important to master so that the diplomatic process and $G$ to $G$ relations and $G$ to people relations run smoothly. NoSQL database is a sophisticated technology that has the ability to respond quickly and accurately at the same time, so it is able to do multiple tasks at once, which we call multitasking. This is where the Ministry needs IT, experts, because the need to operationalize big data is highly dependent on the availability of human resources, servers, software, which are able to access and process infinite amounts of data.

Big data is often referred to as the New Gold (Data is the New Gold), said NeelieKroes, from the European Commission on the Digital Agenda, who says that data is everything, like petroleum, which helps provide transformed data for strategic decision making and accurate, improve performance and productivity.

Character Big Data is a sophisticated technology that has the ability to store and process data that is very complex, various, from the text, images, sound, and other digital traces, with a capacity of billions of terabytes, which are very dynamic and changing, which is summarized in terms of size (volume) that is unlimited, high speed (velocity), and very complex (variety) with capabilities beyond the capabilities of the human brain.

The dynamics and development of big data technology are very fast, especially now that the need for speed and accuracy as well as gigantesque capabilities is urgently needed. Then the MPP database system was created which was able to manage large-scale databases. This means that more than one server and is widely distributed. This is a new finding that supports the SQL system mentioned above. Now the world is competing to find applications capable of working on complex data. So the Map Reduce technology was born, which is capable of analyzing very complex algorithms, so that interactive and retrospective work is done.

These findings require special human resources so that the maintenance and development of Big Data information systems can be done better.

What is provided by Big Data requires goodwill and the provision of adequate funds and human resources.
After all, international relations is the involvement of state actors and state actors in an uncountable number. By knowing the thoughts, movements, actions, and speeches of these actors, the ministry of foreign affairs has sufficient data to determine the attitudes, thoughts, and goals of actors in the arena of international relations. With the knowledge of these actors, policymakers in the Ministry will quickly formulate new strategies and tactics in order to benefit from these actors. This includes information that is blasted on social media, which can be used properly by the Ministry in decision making.

The effectiveness of the mastery of technology in hybrid diplomacy is saving fund (especially if there is a willingness to use Open Source Big Data), increasing data accuracy, increasing speed and accuracy of policies, and being able to increase efficiency in international negotiations, both in bilateral and multilateral negotiations, including the ability to collect data from terrorism movements and activities and trans-national crimes. This is because Big Data is able to analyze geospatial data with high accuracy and real-time.

To achieve a more aggressive and dynamic level of diplomacy, the Ministry of Foreign Affairs must always update its website and changing policies, in order to increase the intensity of relations, commitment, and loyalty of state and non-state actors.

\section{CONCLUSION}

From what has been described above, it can be concluded that the Ministry of Foreign Affairs is obliged to formulate new, more effective and adaptive communication strategies and techniques in the world of hybrid and virtual diplomacy. That international actors are decentralized and spread out, not only state actors but non-state actors, especially the international public, are actively involved in international politics. Therefore, global social networks require special management, especially in terms of crisis management. This is to balance both the competition for radical information, political debates, and radicalism that revolves around the issue of truth claims on a particular problem.

In entering the era of digital diplomacy, technological innovation, and adaptation of the new environment show a conservative mental change towards innovation and virtual adaptation, which radically changes the norms and values of communication and diplomacy. In facing various obstacles, the Ministry of Foreign Affairs is preparing a political platform for all these rapid changes, especially in infrastructure facilitation, human resources, and multi-media creativity to be able to adapt to the needs of hybrid space, such as animation and videography production. 


\section{REFERENCES}

[1] M. Bjiola, Corneliu; Holmes, Digital Diplomacy: Theory and Pract. Routledge, 2015.

[2] J. H. Couloumbis, Theodore A.; Wolfe, PENGANTAR HUBUNGAN INTERNASIONAL: Keadilan dan Power. New Jersey: Prentice Hall, 1986.

[3] S. D. Long, Communication, Relationship, Practices and Virtual Work. New York: Business Science References, 2010.

[4] P. Naisbit, Jhon; Aburdene, Megatrend 2000. London: Sidwick \&Jackson, 1990.

[5] A. Purwasito, Message Studies, Pesan sebagai Penggerak Kebudayaan. Surakarta: Ndalem Poerwahadiningratan, 2003.

[6] J. W. Lull, Media, Communication, Culture: A. Global Approach. Columbia University, 1995.

[7] A. A. Berger, Tanda-Tanda dalam Kebudayaan Kontemporer. Yogyakarta: Tiara Wacana, 2000.

[8] K. W. Morgenthau, Joachim Hans; Thompson, Politics Among Nations, The Struggle for Power and Peace. McGraw Hill, 1985. 